\title{
Limited role for surveillance PET-CT scanning in patients with diffuse large B-cell lymphoma in complete metabolic remission following primary therapy
}

\author{
CY Cheah ${ }^{1,2}$, M S Hofman ${ }^{2,3}$, M Dickinson ${ }^{1,2}$, A Wirth ${ }^{2,4}$, D Westerman ${ }^{1}$, S J Harrison ${ }^{1,2}$, K Burbury ${ }^{1}$, M Wolf W $^{1,2}$, \\ H Januszewicz ${ }^{1}$, K Herbert ${ }^{1,2}$, H M Prince ${ }^{1,2,5}$, D A Carney ${ }^{1,2}$, D S Ritchie ${ }^{1,2}$, R J Hicks ${ }^{2,3}$ and J F Seymour ${ }^{\star, 1,2}$ \\ ${ }^{1}$ Department of Haematology, Peter MacCallum Cancer Centre, East Melbourne, VIC, Australia; ${ }^{2}$ University of Melbourne, \\ Melbourne, VIC, Australia; ${ }^{3}$ Centre for Cancer Imaging, Peter MacCallum Cancer Centre, East Melbourne, VIC, Australia; \\ ${ }^{4}$ Department of Radiation Oncology, Peter MacCallum Cancer Centre, East Melbourne, VIC, Australia and ${ }^{5}$ Monash University, \\ Melbourne, VIC, Australia
}

Background: The usefulness of positron emission tomography with computed tomography (PET-CT) in the surveillance of patients with diffuse large B-cell lymphoma (DLBCL) in complete metabolic remission after primary therapy is not well studied.

Methods: We performed a retrospective review of our database between 2002 and 2009 for patients with de novo DLBCL who underwent surveillance PET-CT after achieving complete metabolic response (CMR) following primary therapy.

Results: Four-hundred and fifty scans were performed in 116 patients, with a median follow-up of 53 (range 8-133) months from completion of therapy. Thirteen patients $(11 \%)$ relapsed: seven were suspected clinically and six were subclinical (all within first 18 months). The positive predictive value in patients with international prognostic index (IPI) $<3$ was $56 \%$ compared with $80 \%$ in patients with $\mathrm{IPI} \geqslant 3$. Including indeterminate scans, PET-CT retained high sensitivity $95 \%$ and specificity $97 \%$ for relapse.

Conclusion: Positron emission tomography with computed tomography is not useful in patients for the majority of patients with diffuse large B-cell lymphoma in CMR after primary therapy, with the possible exception of patients with baseline IPI $\geqslant 3$ in the 18 months following completion of primary therapy. This issue could be addressed by a prospective clinical trial.

Despite improvements in cure rates for patients with diffuse large B-cell lymphoma (DLBCL), up to $40 \%$ relapse, mostly within 18 months from treatment (Armitage, 2007). There is no consensus as to the most appropriate form of post-remission surveillance. Salvage chemotherapy and subsequent high-dose therapy with autologous transplantation is potentially applicable for selected patients up to age 75 and can cure up to $40 \%$ of patients who relapse (Kewalramani et al, 2004 ; Jantunen et al, 2008). However, this approach is less likely to be successful in those in whom relapse occurs early after primary therapy (Gisselbrecht et al, 2010). The established prognostic factors for response to salvage including relapse stage, elevated serum lactate dehydrogenase (LDH) and bulk reflect tumour burden, suggesting early detection may increase the likelihood of cure (Hamlin et al, 2003).

Current guidelines recommend clinical review every 3-6 months after completion of therapy for 5 years and annually thereafter with computed tomography (CT) scans at 6 month intervals up to 2 years (National Comprehensive Cancer Network, 2012; Tilly et al, 2010). Despite this, there is little evidence to support the use of CT with $83-89 \%$ of relapses being detected by

*Correspondence: Professor JF Seymour; E-mail: john.seymour@petermac.org

This study has been presented as a poster at the 53rd Annual Exposition of the American Society of Hematology, Atlanta, December 2012.

Received 27 February 2013; revised 14 May 2013; accepted 10 June 2013; published online 27 June 2013

(C) 2013 Cancer Research UK. All rights reserved 0007-0920/13 
symptoms despite surveillance scans (Weeks et al, 1991; Elis et al, 2002; Guppy et al, 2003). Positron emission tomography combined with computer tomography (PET-CT) has become the modality of choice for initial staging and end of treatment assessment in DLBCL (Hicks et al, 2005; Cheson, 2011). The improved sensitivity of PET-CT suggests advantages over CT in the detection of subclinical relapse. Few studies have examined the role of PET-CT surveillance in patients with DLBCL achieving remission after primary therapy (Zinzani et al, 2009; Petrausch et al, 2010; El-Galaly et al, 2011; Goldschmidt et al, 2011; Abel et al, 2012). Liedtke et al (2006) found patients with subclinical relapse were more likely to have lower second-line IPI (RR 4, 95\% CI 0.58-27.6) with a non-significant trend towards survival benefit (actuarial 5 year survival of $54 \%$ vs $43 \%$; $P=0.13$ ). The aim of our study was to evaluate the role of ${ }^{18} \mathrm{~F}$-fluorodeoxyglucose (FDG) PET-CT scans in the surveillance of patients achieving complete metabolic response (CMR) after primary therapy for DLBCL, and define a risk-adapted strategy for surveillance imaging.

\section{MATERIALS AND METHODS}

We conducted a retrospective review of patients with DLBCL who underwent PET-CT scanning at the Peter MacCallum Cancer Centre. Data collection was compliant with the institutional ethics requirements. In the period analysed, departmental protocol recommended 6-monthly PET-CT scans for patients in CMR, for the first 2 years, and then annually until 5 years after completion of therapy for patients in whom there existed intention to intervene if subclinical relapse was identified. In most cases, this intervention consisted of intensive salvage chemotherapy following by autologous stem cell transplantation. Implementation was at the discretion of the treating physician. We included patients who had a confirmed diagnosis of de novo DLBCL treated at our centre between 1st January 2002 and 31st December 2009 who had achieved CMR at the completion of primary therapy and underwent at least one surveillance PET-CT scan.

We identified 200 patients with DLBCL within the specified time period. Eighty-four were ineligible for the following reasons: histological transformation from a variety of indolent lymphoma subtypes $(n=29)$, no surveillance PET-CT scans performed (predominantly patients aged over 70 or otherwise unfit for intensification, $n=26)$, did not achieve CMR $(n=14)$, end of treatment PET positive for another reason for example, sarcoidosis or infection $(n=7)$, palliative management only $(n=5)$, had prior chemotherapy at another institution $(n=3)$. Only two patients without surveillance PET scans relapsed within 6 months of completing therapy (3.2 and 5.4 months) only one of whom was a suitable candidate for autologous stem cell transplant.

Of the cohort $(n=116)$ analysed, the median was age 59 years (range 16-85), 54\% were male and 51\% had an elevated serum LDH. Eastern Cooperative Oncology Group performance status was $\leqslant 1$ in $96 \%$ of patients, with $<2$ sites of extranodal involvement in $75 \%$ and baseline international prognostic index (IPI; 1993)-determined using PET-CT and bone marrow biopsy was $<3$ in $77(66 \%)$ and $\geqslant 3$ in $37(32 \%)$ of patients. In two patients, baseline IPI could not be calculated due to missing data. Initial immunochemotherapy was R-CHOP (rituximab, cyclophosphamide, doxorubicin, vincristine and prednisolone) in 110 (95\%), while six (5\%) received R-Hyper-CVAD (rituximab, hyper-fractionated cyclophosphamide, vincristine, doxorubicin and dexamethasone) alternating with high-dose methotrexate and cytarabine at the discretion of the treating clinician due to the presence of high-risk features. Sixty-six patients (57\%) received radiotherapy as consolidation for bulky or localised disease.
Data collection. For each patient, we collected baseline characteristics including sex, performance status, age, serum $\mathrm{LDH}$, number of extranodal sites, IPI (A predictive model for aggressive nonHodgkin's lymphoma, 1993), primary therapy, date and details of follow-up PET-CT scans, and follow-up data including the date and site of relapse, type (subclinical or suspected), relapse IPI, biopsy results, second malignancies, cause and date of death.

The primary end point was determination of sensitivity, specificity, positive predictive value (PPV) and negative predictive value (NPV) of PET-CT for the detection of relapse.

${ }^{18}$ F-FDG PET-CTs were obtained on a dedicated PET/CT scanner (Discovery LS, GE Medical Systems, Milwaukee, USA; Discovery STE, GE Medical Systems, Milwaukee, USA or Biograph 64, Siemens Medical Solutions, Knoxville, USA) from the skull-base to upperthigh level, unless there was suspicion or known disease outside this field-of-view. Patients were fasted for $6 \mathrm{~h}$ before administration of $5 \mathrm{MBq} \mathrm{kg}{ }^{-118} \mathrm{~F}-\mathrm{FDG}$, to a maximum of $400 \mathrm{MBq}$ adapted for weight and imaged after $\mathrm{a} \geqslant 60$-min uptake phase.

Definitions. PET reports were reviewed and classified as positive, negative or indeterminate for relapsed lymphoma by one (clinician) investigator blinded to patient outcome. In generating the original PET report, the imaging specialist had access to prior investigation results, including the baseline and post treatment FDG PET-CT studies. It should be noted that the time period covered by the study was mostly before the publication of both the International Harmonisation Project (Juweid et al, 2007) and the Deauville criteria (Meignan et al, 2009). A positive scan suggested relapsed lymphoma, with true-positive results requiring either biopsy confirmation or unequivocal scan progression. A falsepositive scan was refuted by biopsy and/or follow-up showing resolution of areas of increased FDG uptake. A negative scan was interpreted as negative for relapsed lymphoma: true negatives had no clinical relapse and false negatives manifest relapse within 3 months from the date of the scan. Cases in which uncertainty in the interpretation of the scan existed $(n=26)$ were referred to a three member review panel (which included one imaging specialist) and re-scored with majority opinion accepted. For seven scans, no determination could be made and they were recorded as 'indeterminate'. A 'suspected relapse' was defined as relapse preceded by signs, symptoms or other clinical features (such as rising serum LDH). A 'subclinical relapse' was defined as relapse detected without the above features, on the basis of imaging findings.

Statistical analysis. Continuous variables are expressed as median and range and compared using the unpaired $t$-test. Non-normally distributed variables are expressed as median and range, and compared using Mann-Whitney $U$-test. Categorical variables are reported as percentages, and compared using Fisher's exact test. Event-free survival, overall survival (OS) and time to relapse were determined using the method of Kaplan and Meier, with curve comparisons using log-rank analysis. A $P$-value $<0.05$ was considered significant.

Results. In 116 patients, 450 surveillance PET-CT scans were performed with a median of four scans per patient (range 1-10). At 1 st January 2012, with a median of 53 (range 8-133) months follow-up from completion of therapy, 13 patients (11\%) had relapsed and 97 (84\%) remain relapse-free in ongoing complete remission. Features associated with relapse in these patients are displayed in Table 1. Of those who relapsed, eight died from progressive disease and five are in remission after salvage therapy. Six patients died from other causes: gastric cancer $(n=2)$, pneumonia complicating oesophageal cancer $(n=1)$, ruptured abdominal aortic aneurysm $(n=1)$, metastatic squamous cell carcinoma $(n=1)$ and cause unknown, while in clinical remission $(n=1)$. 
Table 1. Factors associated with relapse after achieving a complete remission at the end of therapy (univariate analysis)

\begin{tabular}{|l|c|c|l|}
\hline Variable & $\begin{array}{c}\text { Relapse } \\
\mathbf{n}=13\end{array}$ & $\begin{array}{c}\text { No relapse } \\
\mathbf{n}=103\end{array}$ & $\boldsymbol{P}$-value \\
\hline Median age (years) & 59 & 59 & 0.96 \\
\hline $\begin{array}{l}\text { PET stage 3/4 at } \\
\text { diagnosis }\end{array}$ & $11(84 \%)$ & $35(34 \%)$ & 0.005 \\
\hline PET IPI 3-5 & $8(62 \%)$ & $29(28 \%)$ & 0.02 \\
\hline $2+$ EN sites & $7(54 \%)$ & $22(21 \%)$ & 0.02 \\
\hline ECOG $>1$ & $3(23 \%)$ & $1(1 \%)$ & 0.004 \\
\hline Median LDH (IUI ${ }^{-1}$ ) & 634 & 514 & 0.21 \\
\hline $\begin{array}{l}\text { Abbreviations: EN=extranodal; ECOG=Eastern } \\
\text { IPI=international prognostic index; LDH=lactate dehydrogenase. PET IPI is calculated } \\
\text { using the stage based on PET rather than contrast CT. }\end{array}$ \\
\hline
\end{tabular}

Test performance of PET-CT surveillance scanning. There were 13 true-positive scans, six false positives, no false negatives and 424 true negatives. The PPV was $68 \%$ and the NPV $100 \%$. Of the seven indeterminate scans, six were shown by follow-up to be negative for lymphoma and one was biopsy confirmed to be positive. If we include indeterminate scans by scoring the former as false positives and the latter as false negatives, respectively, test performance remained robust with revised sensitivity $95 \%$, specificity $97 \%$, PPV $60 \%$ and NPV $99 \%$.

However, when considering patients with baseline IPI $\geqslant 3$ $(n=37)$ there were eight true positives, two false positives, no false negatives, 112 true negatives and two indeterminate scans. While sensitivity, specificity and NPV (100\%) were essentially unchanged, the PPV increased to $80 \%$. In patients with baseline IPI $<3$ $(n=77)$, there were five true positives, four false positives, no false negatives, 312 true negatives and five indeterminate scans. This resulted in a lower PPV (56\%). Most relapses (and therefore truepositive scans) occurred within the first 18 months. The number of scans needed to detect one subclinical relapse was analysed as a function of both baseline IPI ( $\geqslant 3 v s<3$ ), as well as time following completion of primary therapy. Averaged over the first 18 months following completion of therapy, 92 scans were performed to detect one subclinical relapse in patients with baseline IPI $<3$, but only 22 scans in patients with baseline IPI $\geqslant 3$ ( 86 scans to detect fur subclinical relapses). Surveillance PET-CT had low yield after 18 months regardless of baseline IPI, with only one (clinically suspected) true-positive result in a patient (baseline IPI 3) from a total of 170 scans (Table 2).

Patterns of relapse. Two-thirds of relapses occurred within 18 months of completing chemotherapy and $85 \%$ within 2 years, with a median time to relapse of 12.8 months. The time distribution of surveillance PET-CT scans in the 13 relapsing patients is displayed in Figure 1.

Relapses were detected clinically in seven patients (54\%) with examination findings $(n=4)$, fever $(n=2)$ or collapse $(n=1)$. Five (71\%) suspected relapses occurred at sites, which were previously uninvolved by DLBCL. PET-CT was concordant in all seven cases, with confirmatory biopsies including one case (intra-abdominal relapse) where PET directed the biopsy. In the remaining six cases, biopsy site was selected clinically. The remaining six relapses were subclinical, with three (50\%) occurring at previously uninvolved sites. Four (67\%) subclinical relapses detected by PET-CT would very likely have been missed by CT alone as either nodal disease was $<15 \mathrm{~mm}(n=2)$ or relapse was extranodal (bony without structural abnormality $n=2)$. There was no difference in OS between the two groups $(P=0.76$, Figure 2$)$. Of six subclinical relapses, four had second-line IPI $<3$ and two cases $\geqslant 3$. Among
Table 2. Distribution of PET-CT results as a function of time elapsed from completion of primary chemotherapy for all patients

\begin{tabular}{|l|r|r|r|r|r|c|c|}
\cline { 2 - 9 } & \multicolumn{7}{|c|}{ Months post treatment } \\
\hline & $\mathbf{0 - 6}$ & $\mathbf{6 - 1 2}$ & $\mathbf{1 2 - 1 8}$ & $\mathbf{1 8 - 2 4}$ & $\mathbf{2 4 - 3 6}$ & $\mathbf{3 6 - 4 8}$ & $\mathbf{4 8}+$ \\
\hline Indeterminate & 1 & 3 & 2 & 0 & 1 & 0 & 0 \\
\hline False positives & 2 & 2 & 1 & 0 & 1 & 0 & 0 \\
\hline $\begin{array}{l}\text { True positives } \\
\text { (suspected) }\end{array}$ & 2 & 3 & 1 & 1 & 0 & 0 & 0 \\
\hline $\begin{array}{l}\text { True positives } \\
\text { (subclinical) }\end{array}$ & 3 & 1 & 2 & 0 & 0 & 0 & 0 \\
\hline True negatives & 91 & 96 & 68 & 50 & 66 & 31 & 22 \\
\hline $\begin{array}{l}\text { Total number } \\
\text { of scans }\end{array}$ & 99 & 105 & 74 & 51 & 68 & 31 & 22 \\
\hline
\end{tabular}

Abbreviation: PET-CT = positron emission tomography with computed tomography.

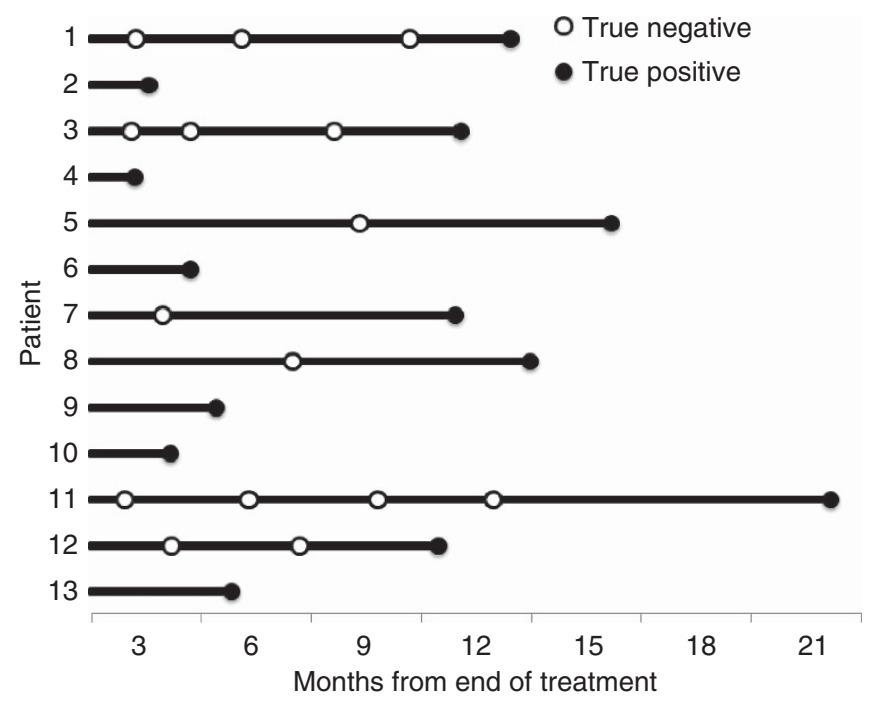

Figure 1. Graphical representation of timing of PET-CT scans performed in the 13 patients who experienced relapse. Follow-up shown until time of relapse; each line represents a single patient. An open circle represents a 'true negative' PET-CT scan that is, demonstrating CMR. A closed circle represents a 'true positive' that is, scan later proven to represent relapsed lymphoma.

seven suspected relapses, four had second-line IPI $<3$, one case second-line IPI was 3 and in two cases not evaluable due to serum $\mathrm{LDH}$ at relapse not being performed. There was no difference in second-line IPI between the two groups $(P=1.00)$.

Management of relapse. The median age of the 13 patients who relapsed (at the time of relapse) was 64 (range 21 to 82) years. All patients received salvage therapy, 11 with R-ICE (rituximab, ifosfamide, carboplatin and etoposide), one (who was 82) with R-CVP and one (who relapsed with follicular histology) with ${ }^{131}$ I-rituxmab (Leahy et al, 2006). Of the 11 patients receiving R-ICE, seven proceeded to cyclophosphamide, carmustine, etopsoide conditioned autologous stem cell transplant. The remaining four patients did not proceed to transplant because their disease was refractory $(n=2)$ or they did not tolerate $(n=2)$ salvage chemotherapy.

Six false-positive scans for recurrent lymphoma occurred at a median of 9.0 (range 3.9-25.1) months following completion of 
treatment. Two false positives were in patients with baseline IPI $\geqslant 3$ and four occurred in those with baseline IPI $<3$. The sites involved were the tonsils $(n=2)$, a cervical lymph node $(n=1)$, mediastinal nodes $(n=2)$ and a peri-duodenal node $(n=1)$. In all cases either biopsy $(n=3)$ or clinical follow-up and resolution $(n=3)$ demonstrated no recurrent lymphoma. There were seven indeterminate scans; two in patients with baseline IPI $\geqslant 3$ and five in patients with baseline IPI $<3$. The sites involved were lung in the setting of a chest infection $(n=1)$, tonsils $(n=2)$, cervical $(n=1)$, suboccipital $(n=1)$, mediastinal $(n=1)$ and inguinal nodes $(n=1)$. In all but the final case (biopsy proven recurrent DLBCL), repeat scanning showed resolution of changes. In the terminology used by Zinzani, there were six 'inconclusive negative' and one 'inconclusive positive' scans (Zinzani et al, 2009). In 67\% of false-positive and indeterminate scans combined, the region of interpretative uncertainty was a nodal site involved on baseline PET-CT.

Second malignancies were detected by surveillance PET-CT in eight (7\%) patients (Table 3). In addition, PET prompted colonoscopy and polypectomy in one patient. There were two false-positive scans suggesting second malignancy, with PET-CT suggesting possible breast cancer in one patient (mammogram suggesting benign fibroadenoma) and colonic cancer in one patient (colonoscopy normal).

\section{DISCUSSION}

Our data suggests that PET-CT scanning has both a low yield, and for most patients with DLBCL achieving CMR at the completion of primary therapy is not justified unless there is clinical suspicion of

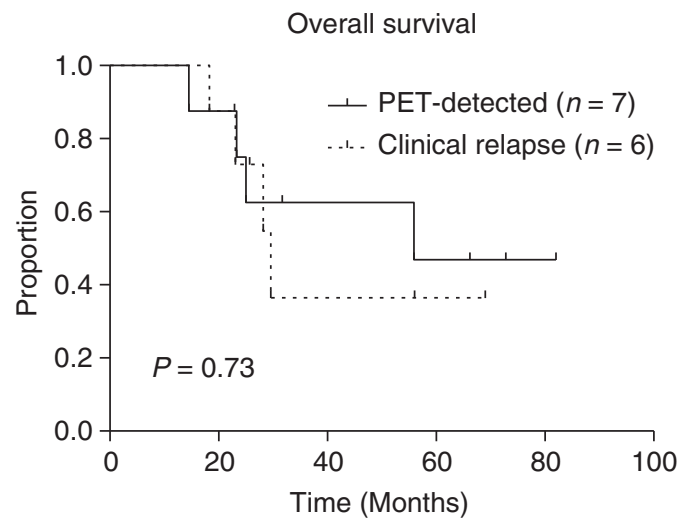

Figure 2. Overall survival by method of detection of relapse, $P=0.73$. relapse. The only potential subgroup in whom a surveillance strategy warrants further investigation is patients with baseline IPI score $\geqslant 3$ in the first 18 months from completion of therapy, when the risk of relapse is greatest. In this study, we did not demonstrate a difference in either second-line IPI or OS for patients with subclinical compared with symptomatic relapse, though the number of relapses was small. Underpinning the desire for earlier detection is the theoretical benefit of better outcomes from salvage therapy (Liedtke et al, 2006), although we acknowledge that poor outcomes seen in this group of patients may reflect aggressive biology rather than late detection of relapse. A prospective study of patients with DLBCL and baseline IPI $\geqslant 3$ in first remission randomised to PET-CT surveillance $v s$ no surveillance with a primary end point of OS would be required to address this issue.

The low rate of relapse among patients achieving CMR at the completion of treatment combined with the lower sensitivity and specificity of CT than PET (Wagner-Johnston and Bartlett, 2011) suggests that diagnostic CT is even less likely to be worthwhile in a surveillance setting. PET-CT detected six (46\%) relapses before clinical manifestations, a numerically greater proportion than using CT alone but still a suboptimal surveillance test (Weeks et al, 1991; Guppy et al, 2003). This could be improved by a shorter time-interval surveillance strategy but this may also increase false positives, cost and radiation exposure. Two-thirds of the subclinical relapses would not have been detected using CT alone, further strengthening the case for use of PET-CT over CT alone in surveillance.

We confirm the finding of other investigators that PET-CT is both sensitive and specific for the detection of relapsed DLBCL (Table 4) (Zinzani et al, 2009; Petrausch et al, 2010; El-Galaly et al, 2011). The NPV of $99-100 \%$ means that patients with negative scans can be reassured that a CMR truly reflects ongoing remission from DLBCL.

False-positive scans were also infrequent, with six (1.3\%) identified. Our findings ( $86 \%$ of inconclusive scans being negative on follow-up) are consistent with the results of Zinzani et al (2009). It is important to recognise common patterns of uptake unlikely to represent lymphomatous recurrence. The majority of false-positive and inconclusive scans occurred in the head and neck or mediastinum, often at sites of lymphomatous involvement at baseline. Increased tonsillar activity is common following chemotherapy, and usually represents reactive lymphoid hyperplasia. Similar findings occur in lymphoid tissue in the mediastinum and para-appendiceal region, with symmetric uptake in the mediastinum and linear uptake in the para-appendiceal region suggesting benign pathology. Mild-to-moderate uptake in cervical nodes, especially following upper respiratory tract infection, should not be mistaken for recurrent lymphoma. It should be highlighted that CT

Table 3. Second malignancies detected by PET-CT during surveillance scanning

\begin{tabular}{|l|l|l|c|l|}
\hline $\begin{array}{l}\text { Age } \\
\text { (years) }\end{array}$ & Sex & Second tumour & $\begin{array}{c}\text { Months post } \\
\text { treatment }\end{array}$ & Outcome \\
\hline 80 & M & Gastric (recurrent) & 7 & Death (pyloric obstruction) \\
\hline 65 & F & Hepatocellular & 25 & Resection, alive in remission \\
\hline 70 & M & SCC & 30 & Palliative radiotherapy, death \\
\hline 62 & M & Oesophageal & 30 & Resection, survived 28 $\mathrm{m}$ \\
\hline 72 & M & Prostate & 6 & Alive, on anti-androgen Rx \\
\hline 63 & M & SCC & 13 & T1N1 left piriform fossa, curative RT \\
\hline 57 & F & Breast & 5 & Mastectomy, alive in remission \\
\hline 81 & F & Breast & 6 & Lumpectomy/radiotherapy $\rightarrow$ remission, death cause unknown 50 months \\
\hline
\end{tabular}

Abbreviations: $\mathrm{F}=$ female; $\mathrm{M}=$ male; $\mathrm{PET}-\mathrm{CT}=$ positron emission tomography with computed tomography; $\mathrm{SCC}=$ squamous cell carcinoma 
Table 4. Existing literature on the use of PET-CT in post-remission surveillance of diffuse large B-cell lymphoma

\begin{tabular}{|c|c|c|c|c|c|c|c|c|}
\hline Author & $\begin{array}{c}n \\
(\% \text { DLBCL) }\end{array}$ & Surveillance protocol & $\begin{array}{l}\text { Median F/U } \\
\text { (months) }\end{array}$ & Type & $\begin{array}{l}\text { Subclinical } \\
\text { relapses }\end{array}$ & $\begin{array}{c}\text { False } \\
\text { positives } \\
\text { (\%) }\end{array}$ & PPV & NNS \\
\hline $\begin{array}{l}\text { Zinzani et al } \\
\text { (2009) }\end{array}$ & $421(43 \%)^{a}$ & $\begin{array}{l}\text { 6-monthly for } 2 \text { years, then } \\
\text { annual for } 2 \text { years }\end{array}$ & 39 & prospective & $31 \%$ & $\begin{array}{l}16 / 1789 \\
(0.9 \%)\end{array}$ & NR & NR \\
\hline $\begin{array}{l}\text { Petrausch } \\
\text { et al (2010) }\end{array}$ & 75 (100\%) & Non standard & 16.5 & Retrospective & $13 \%$ & NR & $85 \%$ & NR \\
\hline $\begin{array}{l}\text { Goldschmidt } \\
\text { et al (2011) }\end{array}$ & 125 (65\%) & Non standard & NR & Retrospective & $38 \%$ & NR & NR & NR \\
\hline $\begin{array}{l}\text { El-Galaly et al } \\
\text { (2011) }\end{array}$ & $52(83 \%)$ & $\begin{array}{l}6 \text { monthly for } 2 \text { years, then } \\
\text { annual for } 3 \text { year }\end{array}$ & 18 & Retrospective & $100 \%$ & $\begin{array}{l}15 / 138 \\
(10.3 \%)\end{array}$ & $21 \%$ & 34.5 \\
\hline $\begin{array}{l}\text { Abel et al } \\
\text { (2012) }\end{array}$ & 625 (100\%) & Non standard & 60 & Retrospective & $26 \%$ & NR & NR & 120 \\
\hline Current study & $116(100 \%)$ & Non standard & 53 & Retrospective & $46 \%$ & $6 / 456(1.3 \%)$ & $\begin{array}{l}|P|<356 \% \\
|P| \geqslant 380 \%\end{array}$ & $\begin{array}{l}\mid \mathrm{PI}<392 \\
\mid \mathrm{PI} \geqslant 322\end{array}$ \\
\hline
\end{tabular}

alone would have missed two-thirds of subclinical relapses and, therefore, cannot be recommended as an alternative surveillance strategy.

We have not made formal economic evaluation of surveillance PET-CT imaging, however health resources are scarce and in the real world must be considered when recommending any surveillance procedures. The true cost of surveillance includes not only that of the PET-CT scans themselves (an amount which varies considerably between health systems) but the additional costs of investigating indeterminate or false-positive scans (either with repeat interval scanning or unnecessary biopsy). Another potential harm of surveillance PET-CT is additional radiation exposure. The radiation dose varies depending on the $\mathrm{CT}$ protocol and sex of the patient, but typically from a combined modality scan of the body is approximately $12-15 \mathrm{mSv}$ per scan (Murano et al, 2011). The subsequent risk of second malignancy is highest in younger patients, and particularly in adolescents and young adults minimisation of radiation exposure should be an important consideration when determining the risks and benefits of a surveillance strategy (Rathore et al, 2012). Surveillance PET-CT scanning detected second primary malignancies in eight patients (7\%), leading to curative procedures in four. Whether this impacted on mortality is uncertain, as these may have been detected without PET. We acknowledge that detection of second malignancies does not constitute a reason to perform surveillance PET-CT, however it is a useful by-product.

Our data has limitations as a retrospective study. We took great lengths to ensure data quality, however, some information is nevertheless missing or incomplete. Although we had departmental recommendations for post-remission scanning, adherence was non-uniform; accordingly our results reflect time periods rather than a precise schedule. We observed refinement in reporting styles of nuclear medicine physicians over time, with greater recognition of phenomena such as the characteristic appearance of rebound lymphoid hyperplasia in recent compared with earlier reports, but our analyses are based on the actual report generated at the time of the scan. Finally, our findings with regard to the performance characteristics of surveillance PET-CT scans are specific to our setting, an academic tertiary referral centre with high imaging volume and physician expertise.

Conclusion. Surveillance PET-CT has no role in patients with DLBCL in achieving CMR with the possible exception of patients with baseline IPI $\geqslant 3$ in the 18 months following completion of primary therapy. A prospective study would be required to address this.

\section{ACKNOWLEDGEMENTS}

CC is funded by a grant from the Victorian Cancer Agency and a New Investigator Scholarship, awarded by the Haematology Society of Australia and New Zealand.

\section{AUTHOR CONTRIBUTIONS}

CC collected and interpreted the data and wrote the manuscript. JFS designed the study, interpreted the data and wrote the manuscript. $\mathrm{MH}$ and $\mathrm{RJH}$ interpreted the data and wrote the manuscript. MD, DW, DSR, DAC, KH, HMP, KB and $\mathrm{SH}$ provided patients and wrote the manuscript.

\section{REFERENCES}

A predictive model for aggressive non-Hodgkin's lymphoma (1993) The International Non-Hodgkin's Lymphoma Prognostic Factors Project. $N$ Engl J Med 329(14): 987-994.

Abel GA, Vanderplas A, Rodriguez MA, Crosby AL, Czuczman MS, Niland JC, Gordon LI, Millenson M, Zelenetz AD, Friedberg JW, LaCasce AS (2012) High rates of surveillance imaging for treated diffuse large B-cell lymphoma: findings from a large national database. Leuk Lymphoma 53(6): 1113-1116.

Armitage JO (2007) How I treat patients with diffuse large B-cell lymphoma. Blood 110(1): 29-36.

Cheson BD (2011) Role of functional imaging in the management of lymphoma. J Clin Oncol 29(14): 1844-1854.

El-Galaly T, Prakash V, Christiansen I, Madsen J, Johansen P, Boegsted M, Johnsen HE, Bukh A (2011) Efficacy of routine surveillance with positron emission tomography/computed tomography in aggressive non-Hodgkin lymphoma in complete remission: status in a single center. Leuk Lymphoma 52(4): 597-603.

Elis A, Blickstein D, Klein O, Eliav-Ronen R, Manor Y, Lishner M (2002) Detection of relapse in non-Hodgkin's lymphoma: role of routine follow-up studies. Am J Hematol 69(1): 41-44. 
Gisselbrecht C, Glass B, Mounier N, Singh Gill D, Linch DC, Trneny M, Bosly A, Ketterer N, Shpilberg O, Hagberg H, Ma D, Briere J, Moskowitz CH, Schmitz N (2010) Salvage regimens with autologous transplantation for relapsed large B-cell lymphoma in the rituximab era. J Clin Oncol 28(27): 4184-4190.

Goldschmidt N, Or O, Klein M, Savitsky B, Paltiel O (2011) The role of routine imaging procedures in the detection of relapse of patients with Hodgkin lymphoma and aggressive non-Hodgkin lymphoma. Ann Hematol 90(2): 165-171.

Guppy AE, Tebbutt NC, Norman A, Cunningham D (2003) The role of surveillance CT scans in patients with diffuse large B-cell non-Hodgkin's lymphoma. Leuk Lymphoma 44(1): 123-125.

Hamlin PA, Zelenetz AD, Kewalramani T, Qin J, Satagopan JM, Verbel D, Noy A, Portlock CS, Straus DJ, Yahalom J, Nimer SD, Moskowitz CH (2003) Age-adjusted International Prognostic Index predicts autologous stem cell transplantation outcome for patients with relapsed or primary refractory diffuse large B-cell lymphoma. Blood 102(6): 1989-1996.

Hicks RJ, Mac Manus MP, Seymour JF (2005) Initial staging of lymphoma with positron emission tomography and computed tomography. Semin Nucl Med 35(3): 165-175.

Jantunen E, Canals C, Rambaldi A, Ossenkoppele G, Allione B, Blaise D, Conde E, Tilly H, Cook G, Clark F, Gallamini A, Haynes A, Mounier N, Dreger P, Pfreundschuh M, Sureda A, Party ftELW (2008) Autologous stem cell transplantation in elderly patients ( $\geqslant 60$ years) with diffuse large B-cell lymphoma: an analysis based on data in the European Blood and Marrow Transplantation registry. Haematologica 93(12): 1837-1842.

Juweid ME, Stroobants S, Hoekstra OS, Mottaghy FM, Dietlein M, Guermazi A, Wiseman GA, Kostakoglu L, Scheidhauer K, Buck A, Naumann R, Spaepen K, Hicks RJ, Weber WA, Reske SN, Schwaiger M, Schwartz LH, Zijlstra JM, Siegel BA, Cheson BD (2007) Use of positron emission tomography for response assessment of lymphoma: consensus of the imaging subcommittee of international harmonization project in lymphoma. J Clin Oncol 25(5): 571-578.

Kewalramani T, Zelenetz AD, Nimer SD, Portlock C, Straus D, Noy A, O'Connor O, Filippa DA, Teruya-Feldstein J, Gencarelli A, Qin J, Waxman A, Yahalom J, Moskowitz CH (2004) Rituximab and ICE as second-line therapy before autologous stem cell transplantation for relapsed or primary refractory diffuse large B-cell lymphoma. Blood 103(10): 3684-3688.

Leahy MF, Seymour JF, Hicks RJ, Turner JH (2006) Multicenter phase II clinical study of iodine-131-rituximab radioimmunotherapy in relapsed or refractory indolent non-Hodgkin's lymphoma. J Clin Oncol 24(27): 4418-4425.
Liedtke M, Hamlin PA, Moskowitz CH, Zelenetz AD (2006) Surveillance imaging during remission identifies a group of patients with more favorable aggressive NHL at time of relapse: a retrospective analysis of a uniformly-treated patient population. Ann Oncol 17(6): 909-913.

Meignan M, Gallamini A, Meignan M, Gallamini A, Haioun C (2009) Report on the First International Workshop on Interim-PET-Scan in Lymphoma. Leuk Lymphoma 50(8): 1257-1260.

Murano T, Minamimoto R, Senda M, Uno K, Jinnouchi S, Fukuda H, Iinuma T, Tsukamoto E, Terauchi T, Yoshida T, Oku S, Nishizawa $S$, Ito K, Oguchi K, Kawamoto M, Nakashima R, Iwata H, Inoue T (2011) Radiation exposure and risk-benefit analysis in cancer screening using FDG-PET: results of a Japanese nationwide survey. Ann Nuc Med 25(9): 657-666.

National Comprehensive Cancer Centre Network. Non-Hogdkin Lymphoma Clinical Practice Guidelines version 2 (2012) .

Petrausch U, Samaras P, Haile SR, Veit-Haibach P, Soyka JD, Knuth A, Hany TF, Mischo A, Renner C, Schaefer NG (2010) Risk-adapted FDG-PET/CT-based follow-up in patients with diffuse large B-cell lymphoma after first-line therapy. Ann Oncol 21(8): 1694-1698.

Rathore N, Eissa HM, Margolin JF, Liu H, Wu MF, Horton T, Kamdar K, Dreyer Z, Steuber P, Rabin KR, Redell M, Allen CE, McClain KL, Guillerman RP, Bollard CM (2012) Pediatric Hodgkin Lymphoma: are we over-scanning our patients? Ped Hematol-Oncol 29(5): 415-423.

Tilly H, Dreyling M. Group ObotEGW (2010) Diffuse large B-cell non-Hodgkin's lymphoma: ESMO Clinical Practice Guidelines for diagnosis, treatment and follow-up. Ann Oncol 21(suppl 5): v172-v174.

Wagner-Johnston ND, Bartlett NL (2011) Role of routine imaging in lymphoma. J Natl Compr Canc Netw 9(5): 575-584 (quiz 585).

Weeks JC, Yeap BY, Canellos GP, Shipp MA (1991) Value of follow-up procedures in patients with large-cell lymphoma who achieve a complete remission. J Clin Oncol 9(7): 1196-1203.

Zinzani PL, Stefoni V, Tani M, Fanti S, Musuraca G, Castellucci P, Marchi E, Fina M, Ambrosini V, Pellegrini C, Alinari L, Derenzini E, Montini G, Broccoli A, Bacci F, Pileri S, Baccarani M (2009) Role of $[18 \mathrm{~F}]$ fluorodeoxyglucose positron emission tomography scan in the follow-up of lymphoma. J Clin Oncol 27(11): 1781-1787.

This work is published under the standard license to publish agreement. After 12 months the work will become freely available and the license terms will switch to a Creative Commons AttributionNonCommercial-Share Alike 3.0 Unported License. 